\title{
Comparative study of serum electrolyte levels between uncomplicated and complicated (Severe) malarial patients
}

\author{
Ummed Singh Solanki ${ }^{1}$, Rumana Khan ${ }^{2}$,* \\ *Corresponding Author: \\ Email: rukhan1994@gmail.com
}

Assistant Professor, Dept. of Biochemistry, Gandhi Medical College, Bhopal, Madhya Pradesh, India

Received: $13^{\text {th }}$ February, 2018

Accepted: $16^{\text {th }}$ March, 2018

\begin{abstract}
Malaria is one of the most important public illness in India. It's a mosquito borne disorder which spreads by the bite of the anopheles mosquito. Electrolytes (sodium\& potassium) are very important for the normal functioning of the human body. Electrolyte disturbances are seen in difficult complicated (severe) malaria. However very few studies have been done on uncomplicated malarial patients and outcome published are contrasting so we decided to undertake this study. We determined the serum electrolyte levels in 25 uncomplicated and 25 complicated malarial patients. Majority of complicated malarial sufferers had hyponatremia and hypokalemia in comparison with uncomplicated malarial patients and the difference between the two groups was statistically significant. It was concluded that hyponatraemia and hypokalaemia are long-established in malaria and they're chiefly associated with the complicated (severe) varieties of falciparum and vivax malaria than with uncomplicated malaria.
\end{abstract}

Keywords: Malaria, Electrolytes, Sodium (Na), Potassium (K).

\section{Introduction}

Malaria is a mosquito borne disease. It spreads by the bite of anopheles mosquito and rarely using blood transfusion. There are 4 species of Plasmodium which causes malaria in humans. The species are P.Falciparum, P.Vivax, P.Malariae and P.Ovale. ${ }^{1}$ Among these 4 species, P.Falciparum is more dangerous and more responsible for mortality and extreme problems, which include cerebral malaria, anaemia and renal failure. Clinical manifestations of uncomplicated malaria vary extensively but are more commonly characterized by fever with rigor, headache and myalgia. ${ }^{2}$

Malaria is an importtiant public illness in term of morbidity and mortality, causing more than 200 million cases each year. ${ }^{3}$ Consistent with the WHO World Malaria report 2017, an estimated 216 million cases of malaria and 445000 malaria deaths passed off in 2016 worldwide. Out of 216 million cases of malaria that befell worldwide in 2016, India account for six percentage. Seven percentage of all the malariaassociated deaths happened in India in 2016. India recorded the most number of deaths in the Southeast Asian region. India stands third in the list of 15 countries that contributed to eighty percentage of the global malaria burden. About $4 \%$ of estimated cases globally have been triggered by using P. Vivax, but outside the African continent this percentage was once $36 \%$. India was first among six nations, as opposed to Ethiopia, Afghanistan, Indonesia and Pakistan - that reported 85 percent of vivax malaria cases. ${ }^{4}$

Sodium $(\mathrm{Na})$ is a predominant cation within the plasma. It forms about ninety percent of $154 \mathrm{mmol} / \mathrm{L}$ of inorganic cation within the ECF. It is accountable for keeping normal distribution of water and osmotic pressure within the ECF. The normal concentration of $\mathrm{Na}$ in the body is $135-145 \mathrm{mmol} / \mathrm{L}$. Potassium is abundantly found within the ICF. The normal concentration is $3.5-5.5 \mathrm{mmol} / \mathrm{L}$. The excessive concentration in ICF is due to the fact that potassium diffuses slowly outward through the cell membrane as $\mathrm{Na}^{+}-\mathrm{K}^{+}$ATPase pump proceed to transport potassium into the cell. The physiologic role of potassium is in the regulation of muscular movements through generation of action potentials and nerve impulse transmission. ${ }^{5}$

Disorders of water and electrolyte balance comprise hyponatreamia, hypernatraemia, hypokalaemia and hyperkalaemia, which also arise in severe malaria infection. Kakkilaya, et al. Showed in his study that malaria is usually related to abnormalities of fluid, electrolytes (Na and $\mathrm{K}$ ) and acid-base balance. ${ }^{6}$ These can occur in any person but are extra customary in severe falciparum malaria, extremes of age and in patients with high degree of fever and vomiting. ${ }^{7}$

Electrolyte imbalance correction in most of the circumstances of malaria is of great significance in management of patient. Timely intervention may reduce the morbidity and mortality of the patients. Many studies have been performed on sodium and potassium levels in complicated malarial sufferers and results showed that there are disturbances in electrolyte levels in them. On the other hand very few studies have been done on uncomplicated malarial sufferers and results published are contrasting so we determined to undertake this study. 


\section{Materials and Methods}

This study used to be conducted in the department of Biochemistry, Medicine and Pathology, Gandhi Medical College and Hamidia Hospital Bhopal from July 2017 to September 2017.

The study comprised of 50 adult malarial patients in the age group of 18-60 years. The patients have been taken from outpatients and inpatients division of Medicine Department who had been satisfying the inclusion standards. As per WHO criteria patients were divided into 2 categories uncomplicated and complicated (severe) malarial patients.

Inclusion Criteria: The study group comprised of total 50 subjects, 25 uncomplicated and 25 complicated (severe) confirmed cases of malaria in the age group 18-60 yrs who were willing to take part in the study. We particularly selected those patients who weren't placed on any remedy for malaria and associated condition.

Exclusion Criteria: Cases with other comorbid conditions like Congestive cardiac failure, Cirrhosis of liver, Nephrotic syndrome, Addison's disease, Cushing syndrome, Diabetes mellitus, Diabetes insipidus, Diabetic Ketoacidosis (DKA), Hyperglycemia Hyperosmolar State (HHS), Chronic Renal Failure, patients on diuretic therapy, likely to affect electrolyte status were excluded from the study.

Prior to the commencement, ethical clearance was received from Institutional Ethics Committee, Gandhi Medical College Bhopal. The patients gratifying selection standards were explained in regards to the nature of the study and a written informed consent was obtained.

Patients were interviewed for demographic information such as age, sex, occupation and many others. Histories of an identical complaint in past and current treatment have been noted. Patients had been subjected to a thorough physical examination, vitals (pulse rate, temperature, blood pressure and respiratory rate) and other scientific signs and symptoms suggestive of malaria illness have been noted. Systemic examination was carried out.
Two specimen bottles had been used for each subject. Anticoagulant bottle containing K2 EDTA for malaria parasite test and plain bottle for electrolyte assay. $5 \mathrm{ml}$ blood sample have been accrued by way of sterile vene-puncture from the anti-cubital fossa. The samples in K2 EDTA anticoagulant bottle were confirmed right away for malaria parasite, after staining their thick films with Giemsa stain even as those samples in plain tube have been allowed to clot and clotted sample was centrifuged at 3000rpm for $5 \mathrm{~min}$ to acquire the sera. The sodium and potassium level within the serum were analyzed using CARELYTE electrolyte analyzer. The instrument was based on Ion Selective Electrode principle.

\section{Statistical Analysis}

The Statistical software SPSS 15.0 was used for the analysis of the data. Descriptive statistical analysis has been carried out in the present study. Results on continuous measurements were presented on Mean \pm SD and results on categorical measurements were presented in Number (\%). Significance is assessed at 5 $\%$ level of significance. Student $\mathrm{t}$ test (two tailed, independent) has been used to find the significance of study parameters on continuous scale between two groups.

\section{Results}

In this study $56 \%$ and $40 \%$ of the uncomplicated and complicated malarial patients were positive for plasmodium vivax and $40 \%$ and $52 \%$ of the uncomplicated and complicated malarial patients were positive for plasmodium falciparum respectively as shown in table 1 . However, $4 \%$ and $8 \%$ of the uncomplicated and complicated malarial patients were positive for both plasmodium vivax and plasmodium falciparum. Table 2 shows that majority of complicated malarial patients had hyponatremia and hypokalemia compared to uncomplicated malarial patients and the difference between the two groups was statistically significant.

Table 1: Types of malaria in between two groups

\begin{tabular}{|l|c|c|c|c|}
\hline \multirow{2}{*}{ Type of Malaria } & \multicolumn{2}{c|}{ Uncomplicated Malaria Cases } & \multicolumn{2}{c|}{ Complicated Malaria Cases } \\
\cline { 2 - 5 } & No & \% & No & \% \\
\hline Plasmodium vivax & 14 & 56 & 10 & 40 \\
\hline Plasmodium falciparum & 10 & 40 & 13 & 52 \\
\hline $\begin{array}{l}\text { Both (Plasmodium vivax and } \\
\text { plasmodium falciparum) }\end{array}$ & 01 & 04 & 02 & 08 \\
\hline Total & 25 & 100.0 & 25 & 100.0 \\
\hline
\end{tabular}

Table 2: Sodium pottassium levels between two groups

\begin{tabular}{|l|c|c|c|}
\hline \multicolumn{1}{|c|}{ Electrolyte } & $\begin{array}{c}\text { Uncomplicated Malaria } \\
\text { Cases }\end{array}$ & $\begin{array}{c}\text { Complicated } \\
\text { Malaria Cases }\end{array}$ & Significance \\
\hline Sodium & $135.84 \pm 2.8$ & $130.9 \pm 3.20$ & $\mathrm{P}<0.05$ \\
\hline Potassium & $3.71 \pm 0.42$ & $3.11 \pm 0.71$ & $\mathrm{P}<0.05$ \\
\hline
\end{tabular}




\section{Discussion}

Malaria is a life threatening sickness, with almost $1 / 2$ of the world's population being liable to this infection. ${ }^{8}$ Consistent with trendy estimates, released in December 2015, there were 214 million cases of malaria in 2015 with 438,000deaths. ${ }^{9}$ It's a essential well being hazard in India and different tropical countries. In India about 21.98 percent population lives in malaria high transmission (> 1 case/1000 population) areas and about 67 per cent in low transmission (0-1 case/1000 population) areas. ${ }^{10}$ About $91 \%$ of malaria cases and $99 \%$ of deaths due to malaria is reported from north eastern states, Chhattisgarh, Jharkhand, Madhya Pradesh, Odisha, Andhra Pradesh, Maharashtra, Gujarat, Rajasthan, West Bengal and Karnataka. ${ }^{9}$

Electrolytes play an important role in normal physiology of life. Electrolyte disturbances act as a hallmark for the severity of disease, due to the fact they're frequently related to the severe P. Falciparum and P. Vivax malaria. ${ }^{1} \mathrm{Na}$ is among the most important mineral in human body. $\mathrm{Na}$ is crucial for the fluid distribution, blood pressure, cellular work and electrical endeavor of the body. Alteration in $\mathrm{Na}$ level can lead to a couple of well being problems. ${ }^{11}$ Our study indicates that majority of complicated malarial patients had hyponatremia in comparison with uncomplicated malarial patients and the change between the two groups used to be statistically huge. The pathophysiology of hyponatraemia in malaria remains unclear, however several reports have stated that an multiplied secretion of vasopressin (ADH), both accurately or inappropriately, plays an fundamental role within the low degree of sodium in malaria since sodium may just enter into the contaminated cells and result in loss of blood. ${ }^{12}$ Hyponatraemia has been recognized as a normal outcome of malaria. ${ }^{1}$ Ikekpeazu et al. also observed reduction in $\mathrm{Na}$ concentration in malaria patients. ${ }^{13}$ Hyponatraemia has been reported to occur traditionally in patients affected by P. Falciparum malaria than in P.Vivax malaria. ${ }^{1,14}$ Simon brown analysed systematically reports of hyponatraemia in non-falciparum and falciparum malaria. He determined that hyponatraemia was long-established in falciparum malaria, but used to be much less by and large pronounced in non-falciparum malaria. ${ }^{15} 52 \%$ complicated malarial patients have been positive for $\mathrm{P}$. Falciparum in our study which is in agreement with the statement of simon brown. Mean $\mathrm{Na}$ level in uncomplicated malarial patients was $135.84 \pm 3.8$ which used to be near normal it may be due to the fact that we had incorporated patients from outpatient department as well.

Potassium $(\mathrm{K})$ is an essential electrolyte in human body. It is often referred to as mineral of the heart because it directly impacts the heart muscle cells. It's foremost for the usual functioning of nervous system and heart muscle activity. Minor alterations in potassium level can cause weakness, fatigue and fast heartbeat. Consequently, its steadiness may be very primary for the normal physiology of human body. ${ }^{16}$ The findings of our study showed the decline in K level in complicated malarial sufferers. Decline within the degree of $\mathrm{K}$ has been pronounced in various studies. ${ }^{13,17}$ Heindricks et al reported that the reduction in the $\mathrm{K}$ levels was once on account that the host cells misplaced up to 75 to $80 \%$ of their typical potassium content material during the course of the malaria attack. ${ }^{13}$ Acidosis is now known as an foremost element of the severe malaria syndrome and a predictor of fatal end result. Ameliorations in plasma potassium concentrations are most likely associated with acidosis. ${ }^{18}$ Better urinary removal of $\mathrm{K}$ and hypokalemia has been pronounced as common results of malaria. Plasmodium presence may reduce the $\mathrm{K}$ levels and aggravates the problems associated with malaria disorder. P. Falciparum infected individuals has been frequently observed with hypokalaemia as compared to P. Vivax contaminated individuals. ${ }^{1}$ In our study hypokalemia in complicated malarial patients may be because of the fact that we had a good no. of patients positive for $P$. falciparum.

\section{Conclusion}

It may be concluded that hyponatraemia and hypokalaemia are common in malaria and they are certainly associated with the complicated (severe) forms of falciparum and vivax malaria than with uncomplicated malaria.

\section{References}

1. Jasani H. J., Sancheti M.S., et al. Association of the electrolyte disturbances $(\mathrm{Na}+, \mathrm{K}+)$ with the type and severity of the malarial parasitic infection. Journal of Clinical and Diagnostic Research. 2012(Suppl2);6(4):678-681.

2. Rathod S. Study of sodium and potassium ion disturbances in malaria at Ahmedabad, Gujarat, India. International Archives of Integrated Medicine. 2014;1(1):7-11.

3. Autino B, Noris A, Russo R, Castelli F. Epidemiology of malaria in endemic areas. Mediterr J Hematol Infect Dis 2012;4(1):e2012060.

4. World malaria report 2017 World Health Organization.

5. Jimmy E O, Usoh I F and Umoh I. Assessment of Intracellular and Extracellular Fluids (ICG, ECf) Compartments with Antimal, Chloroquine, Coartem, Fansidar and Malareich. Journal of Natural Sciences Research. 2013;3(1):59-63..

6. Kakkilaya BS (1997) Malaria: In Parks Textbook of Preventive and Social Medicine. $\left(15^{\text {th }}\right.$ edn $)$, K Park.

7. Heindricks RG, Hassan AH, Olurinde LO, Akindkani A (1971) Malaria in early childhood. Annals of Tropical Medicine. 65:316-320.

8. Mishra SK, Mohapatra S, Mohanty S, Patel NC, Mohapatra DN. Acute renal failure in falciparum malaria. Journal, Indian Academy of Clinical Medicine. 2002;3:141-47.

9. Park K. Preventive and Social Medicine: 24ed.:Malaria: Pg. No. 271 
10. WHO (2016), Fact sheet on World Malaria Report, April 2016.

11. Fox M (2013). Importance of Sodium. Living Strong Foundation. Available from:

http://www.livestrong.com/article/499403-importance-ofsodium.

12. Hanson J, Hossain A, Charunwatthana P, Hassan MU, Davis TM, Lam SW, Chubb SA, Maude RJ, Yunus EB, Haque G, White NJ, Day NP, Dondorp AM.

Hyponatremia in severe malaria: evidence for an appropriate anti-diuretic hormone response to hypovolemia. Am J Trop Med Hyg,2009;80(1):141-145.

13. Ikekpeazu EJ, Neboh EE, Aguchime NC, Ma-duka IC, Anyanwu EG. A study on malaria parasitemia:-effect on the sodium and po-tassium levels. J Biol Med, 2010;2(2):20-25.

14. Olaniyan MF. The Pattern of Packed Cell Volume, Plasma Electrolytes and Glucose Levels in Patients Infected with Plasmodium falciparum. Afr J Clin Exp Microbiol, 2005;6(2):87-90.

15. Simon Brown. Dysnatraemia in malaria. International Journal of Basic Medical Sciences and Pharmacy. 2012;2(1):1-6
16. Peterson LN. Potassium in nutrition. In: Handbook of nutritionally essential minerals. Eds, O'Dell BL and Sunde RA. Marcel Dekker Inc. New York, 1997 pp. 153183.

17. Yoel C. Clinical symptoms and electrolytes description of children with malaria an outpatient setting in kabupatenmandailing natal. $M K N, 2007 ; 40:(1)$.

18. Maitland K, Pamba A, Newton CR, Lowe B, Levin M Hypokalemia in children with severe falciparum malaria. Pediatr Crit Care Med. 2004;5:81-5.

How to cite this article: Solanki US, Khan R. Comparative study of serum electrolyte levels between uncomplicated and complicated (Severe) malarial patients. Int J Clin Biochem Res. 2018;5(3):427-430. 